\title{
Optimal Management of Glenohumeral Joint Injuries in Athletes Playing Rugby
}

Ian Horsley ${ }^{1^{*}}$ and Lee Herrington ${ }^{2}$

${ }^{1}$ Physiotherapy Department North West region, English Institute of Sport, Manchester M11 3FF, UK

${ }^{2}$ Sports Rehabilitation, Directorate of Sport, Exercise and Physiotherapy, University of Salford, Salford M6 6PU, UK

*Corresponding author: lan Horsley, Physiotherapy Department North West region, English Institute of Sport, Manchester M11 3FF, UK, Tel: +44 161 295 5000; Email: Ian. Horsley@eis2win.co.uk

Rec date: Mar 21, 2014; Acc date: Apr 21, 2014; Pub date: Apr 23, 2014

Copyright: (c) 2014 Horsely A, et al.. This is an open-access article distributed under the terms of the Creative Commons Attribution License, which permits unrestricted use, distribution, and reproduction in any medium, provided the original author and source are credited.

\begin{abstract}
Shoulder injuries within the collision sport of rugby not only result in significant time loss from competition but also have a high reoccurrence rate. Rehabilitation of these athletes forms a critical element in both returning them to sport and reducing the risk of further injury. This review outlines the problems which clinicians encounter in managing these athletes and strategies to overcome them.
\end{abstract}

Keywords: Glenohumeral; Articular; Latissimus

\section{Introduction}

For practitioners of sports medicine rugby players, appear to have the highest risk of injury per exposure time [1-3]. Impact and collisions at speed are fundamental components of the game and are responsible for considerable musculoskeletal trauma [4,5]. Competitive rugby matches involve high velocity contacts within the structure of the game, such as scrums, tackles, rucks and mauls [6,7] and sports-specific injury resulting from cumulative stress to a particular area of the body is a commonly reported injury [8].

Several other authors have highlighted that shoulder injuries are becoming more severe within professional rugby [9-12]. Most incidences of shoulder joint instability are the result of traumatic contact injuries like force or falling on an outstretched arm or a direct blow to the shoulder area [13].

Athletes need shoulders with appropriate levels of functional mobility and stability necessary to cope with the speeds, loads, ranges and repetitions of their sports. In a collision sport an athlete has to decelerate high eccentric forces necessary within the contact situation [14]. Both static and dynamic stabilizers are involved in maintaining glenohumeral joint stability. Static stabilizers include the glenoidlabrum, the glenohumeral ligaments and capsule, the articular surface of the glenoid and the negative intra-articular pressure within the joint. Dynamic stabilizers include the rotator cuff and periscapular musculature. A balance between static and dynamic stabilizers as well as coordinated contraction of rotator cuff muscles is important for glenohumeral stability. Blanch [15] described the concept of Functional Stability Threshold (FST) which consists of mechanical and neuromuscular interplay, which helps maintain the humeral head within the centre of the glenoid. The ability to maintain the humeral head within the centre of the joint is essential to establish during the assessment and rehabilitation of the contact shoulder. A total of $1-2 \mathrm{~cm}$ of uncontrolled humeral head translation can be the difference between a symptomatic and asymptomatic shoulder due to impingement or instability [16]. When the mechanical static restraints fail, greater demands are placed on the neuromuscular system to actively maintain FST, which may result in sub-optimal compensatory movement patterns producing rigidity, fatigue and ultimately an inability to optimally maintain dynamic joint stability [15].

If the neuromuscular system fails, the glenohumeral joint is exposed to increased shear and compressive forces, which may also lead to damage the mechanoreceptors and to deafferentation [17] which reduces the afferent nerve supply from the joint to the central nervous system (CNS) and alters the feedback mechanism for dynamic joint stabilization. The neuromuscular system incorporates the feedback loops involving the articular and musculotendinous mechanoreceptors which are integrated within the CNS [18]. The failure of the active control system in the literature has been considered as a contributor to the failure of proprioception [19]. The term proprioception involves a combination of Joint Position Sense (JPS) and kinaesthesia (the perception of motion). JPS has been shown to be necessary for normal muscle coordination and timing, especially where active muscle forces play a significant role $[20,21]$. It contributes to the maintenance of protective muscle stiffness and coordination about a joint and is affected by structural alterations such as ligament damage and surgery.

Several modifiable factors have been reported to influence JPS including training, joint range, and fatigue. Fatigue leads to nervous system alterations, which lengthen the muscle spindles so when the stretch stimulus arrives, the muscle spindle is not at the expected length, and affects the spindle output creating an inappropriate cascade that ultimately results in injury. Whilst we know that JPS is reduced when fatigue occurs, the effect only seems to be found in relation to end-of-range positional acuity, with JPS in the mid-range not changing [22]. If, following repeated tackling, the mechanoreceptors are unable to accurately report shoulder position in the outer range (stretch) position as reported in the study of Herrington et al. [22], there is a potential for the anterior structures to become stressed before any compensatory / protective muscle contraction can take place. These deficits are proposed to contribute to overuse injuries and micro-instability of the glenohumeral joint, which may be related to the increasing rate of shoulder injuries in rugby.

In addition to the role of proprioception in maintaining local joint stability, it is also essential for co-ordination of multi joint movement sequences, and regulating the contraction of distal segment muscles to control proximally generated forces [23]. This is demonstrated by the hyper angulated position of the humerus when it is in a position of 
horizontal extension relative to the scapula plane. This provides the system with a significant control challenge and injury risk, not only in the rugby tackle, but also in throwing activities [17]. This has important implications for retraining and exercise specificity.

Like any joint injury, rehabilitation following an injury to the shoulder includes relevant pain management, reduction of inflammation, restoration of optimal muscle strength, and restoration of a functional joint range of motion. Rehabilitation should also progress along a continuum to include functional movements which replicate the demands of the sport. This progression is underpinned by a fundamental requirement for joint control and as such, there is an inherent need to address proprioceptive awareness, dynamic stabilization, feed-forward mechanisms (through anticipatory muscle responses), and reactive muscle function to athletic demands [24]. It has been suggested that proprioceptive training re-connects the afferent pathways from the joint to the central nervous system with the production of complimentary afferent responses as a compensation for the joint position deficits produced by fatigue and/or injury [25]. With shoulder joint injury, the resultant impact on the sensory motor system which is responsible for motor control and proprioception is a key factor in the success of any rehabilitation pathway, as demonstrated following shoulder injuries in rugby [26].

\section{Restoration of Functional Range of Motion}

It is important that a full functional range of motion is restored in the shoulder; restriction in one direction has the potential to lead to 'give' (excessive joint play) in another. In throwing shoulders a significant reduction in internal rotation range (Glenohumeral Internal Rotation Deficit (GIRD) has been reported as a reliable predictor of shoulder injury and impingement symptoms [27,28]. Rotational loss due to capsular contracture is evident when the GIRD exceeds that which can be explained by bony remodelling alone (over 12 degrees) and when the internal rotational loss exceeds the external rotational gain compared to the contralateral shoulder [29]. Although in rugby, there is little which resembles throwing, the rugby shoulder can show evidence of a loss of internal rotation due to functional alterations in the posterior cuff musculature.

Posterior shoulder tightness, created by an inability of the shoulder to balance and absorb the stresses created by the high deceleration forces, is often a result of hyper tonicity in the posterior cuff. Tightness of the posterior cuff has been shown to have a very high tendency to increase the posterior or the superior humeral head translation in the late cocking position of throwing [30]. This alteration in glenohumeral mechanics could also be a factor during tackling and passing in rugby. Investigators have credited this alteration in motion to a stretching of the anterior capsule, and tightening of the posterior capsule [31-33], nevertheless, contemporary research shows that the posterior capsule does not tighten, but thickens [34]. Another consideration is that previous studies have reported that internal rotator fatigue causes a deficit in proprioception [35,36] and affects scapula joint kinematics [37,38].

Manual therapy and self-stretching techniques (sleeper stretch) aimed at restoration of normal tone are vital for improving the lengthtension relationships acting locally at the glenohumeral joint $[39,40]$. Limited data exist on the stretching techniques for the posterior capsule, although some investigators have examined the Cross-Body Stretch and the Sleeper Stretch [40-42]. After the completion of a stretching protocol in one study, each subject's R.O.M. was reassessed.
The Cross-Body Stretch subjects demonstrated statistically significant improvement in R. O. M. (across the group) relative to the control group, whereas the Sleeper Stretch group did not show a group increase in ROM [42].

In addition to measures of posterior cuff tightness, the measure of total range of motion in a shoulder is also of importance. A loss of five degrees total range relative to the contralateral arm has been associated with shoulder symptoms in throwing athletes $[43,44]$. As an example, in an anteriorly unstable shoulder, a lack of underlying neuromuscular stability provided by the rotator cuff to prevent anterior shear as the arm reaches positions of hyper angulation and abduction with external rotation can cause compensation, which could be manifest at the tackle. Overuse and dominance of the larger internal rotator muscle groups to protect the shoulder joint, often used as a compensatory strategy [45], can destabilise the joint further and result in a reduction of functional range. The compensatory muscle actions of larger muscle groups (e. g. latissimusdorsi and pectoralis major) will have an impact on other areas of the kinetic chain (thoracic and lumbar spine and pelvis) and must be addressed both locally and globally. The ability of a throwing athlete to achieve the cocking position of the arm or a rugby player to be in the set position for a tackle is made up not only of glenohumeral joint rotation, but also scapula and thoracic spine mobility. It is important to incorporate stretching that addresses such restrictions throughout the kinetic chain, as with the thoracic spine and latissimusdorsi in the combined elevation rollout [46]. Tightness in latissimusdorsi in this stretch can result in an inability to externally rotate the shoulder required for full elevation and also negatively impact on optimizing spinal mobility and stability. In the rugby player this is likely to result in a local anterior and inferior pull to the humeral head and downward rotation and anterior tipping of the scapular and a flexed and ipsilaterally side flexion lumbar and thoracic spine.

\section{Restoration of the Sensory motor System}

Rehabilitation needs to be able to replicate the demands placed on the joint, under controlled conditions. Identifying deficits within the sensory motor system in a clinical setting is not easy, however. Within scientific literature sophisticated equipment such as isokinetic dynamometers, EMG and motion analysis video capture have been utilised. But these devices are not readily available in a clinical setting and thus render these techniques impractical. There is a need for valid, reliable and repeatable clinic based tests. The following assessment tools provide some options when testing proprioception for the upper limb. Open chain and closed chain examples are important to assess the varying requirements of the shoulder in terms of athletic function.

\section{Open Chain Assessment}

The majority of athletic shoulder tasks are performed in an open chain (OC) manner, that is, with the distal segment free. Striking and throwing sports provide us with the most common examples. It is critical, therefore, than an OC assessment forms a large part of both evaluation and rehabilitation protocols.

Joint angle repositioning (JAR) - The shoulder joint is taken to a specific position in space (generally a combination of abduction and external rotation) by the examiner. The subject (who has their eyes closed in order to negate visual cues) is asked to hold this position for 5 seconds (Figures 1 and 2), then the limb is moved to the starting position, and the subject is asked to move to the test position. The 
degree of error from the stated position is recorded. This test assesses both the static and dynamic shoulder joint stabilisers, providing a thorough afferent pathway assessment.

Contralateral arm mirroring (CLAM) - the subject's uninvolved shoulder is placed in a position in space (whilst they have their eyes closed) and the subject is asked to mirror that position with the "involved" limb. The degree of error (positional difference) between the two sides is noted.

Dynamic Rotary Stability Test (DRST) and Dynamic Relocation Test (DRT) - Magarey and Jones $[47,48]$ reported a functional clinic based test that monitors humeral head control and rotator cuff activation through range, assessing directional control deficits as the athlete is required to stabilise their shoulder under progressively more challenging situations. This test can be adapted to replicate the point in the range that the athlete experiences their symptoms (pain, weakness, apprehension or instability). Retraining of an identified control dysfunction by using dynamic relocation test as a treatment tool can alter athlete's symptoms and overall presentation on reassessment. Successful retraining through this method is a clinical indication that it is worth persevering with a conservative rehabilitation programme. Magarey et al. [47] advocated their tests for use in subtle situations where instability is more functional than structural.

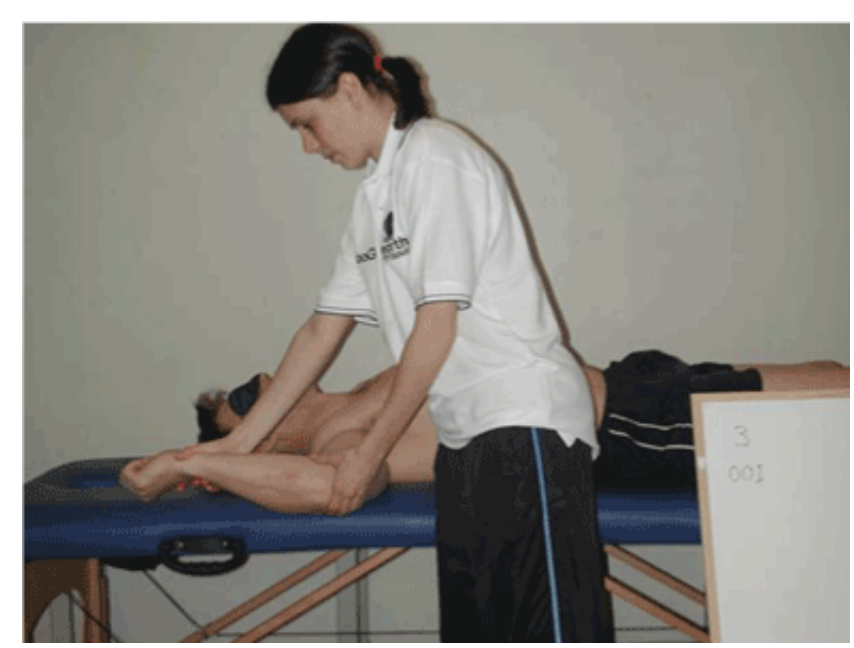

Figure 1: Joint angle repositioning, combination of abduction and external rotation

\section{Closed Chain Assessment}

Joint position reproduction can be utilised in closed chain situations such as four-point kneeling. The subject is asked to replicate the position that they are placed in with both upper limbs in contact with the support surface (Figures 3 and 4).

A four point kneeling assessment of proprioception has been progressed to a measure of postural sway of a single arm perturbation task as measured using a force platform [49]. The test measures antero-posterior and medio-lateral sway variation as a marker of an athlete's ability to balance on an unstable surface. Initial results of such tests have shown a reduction in postural sway measures after training aimed at improvement in single arm closed chain activity.

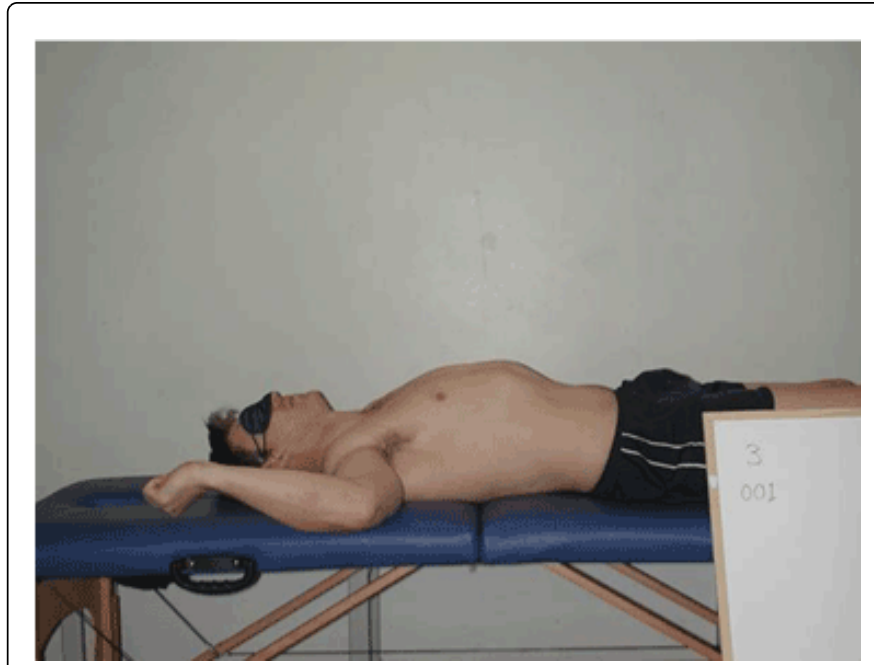

Figure 2: Joint angle repositioning

\section{Rehabilitation Programming}

The progression of a rehabilitation programme should progress along a continuum of difficulty with respect to the sport or desired activity, and in most cases should evolve from bilateral to unilateral; supported to unsupported utilising active and passive movement; with and without load. This can be seen in Table 1, below.

\begin{tabular}{|l|l|l|}
\hline & Early Stress & End Stage \\
\hline Support & $\begin{array}{l}\text { Supported } \\
\text { Bilateral }\end{array}$ & $\begin{array}{l}\text { Unsupported } \\
\text { Unilateral }\end{array}$ \\
\hline Surface & Stable & Unstable \\
\hline Stress & $\begin{array}{l}\text { Minimal Capsular Stress } \\
\text { Mid-Range }\end{array}$ & $\begin{array}{l}\text { Maximal Capsular Stress } \\
\text { Outer Range }\end{array}$ \\
\hline Speed & Slow & Fast \\
\hline Stress Application & $\begin{array}{l}\text { Predetermined / Slow } \\
\text { progressive stress }\end{array}$ & Random/Rapid Stress \\
\hline Movement Pattern & Simple Co-ordination & Complex Co-ordination \\
\hline
\end{tabular}

Table 1: Rehabilitation Continuum

\section{Closed Chain Rehabilitation}

The use of closed chain assessments of proprioception and movement patterns around the shoulder highlight deficits, which can be targeted and addressed through closed chain rehabilitation exercises. Weight bearing exercises through the limb facilitate the activity of the rotator cuff muscles in safe and congruent positions for the shoulder joint, and can be utilised in positions of forward lean standing against a wall, or in four point kneeling. These can be progressed to a three point position (by extending the other arm or either leg) and further progressed to two point weight bearing which will facilitate the posterior chain to aid with scapular stabilisation as well as assisting with specific recruitment of scapula stabilisers such as serrates anterior or lower and middle trapezius. 
Citation: Horsley I and Herrington L (2014) Optimal Management of Glenohumeral Joint Injuries in Athletes Playing Rugby. J Trauma Treat 3: 193. doi:10.4172/2167-1222.1000193

Page 4 of 8

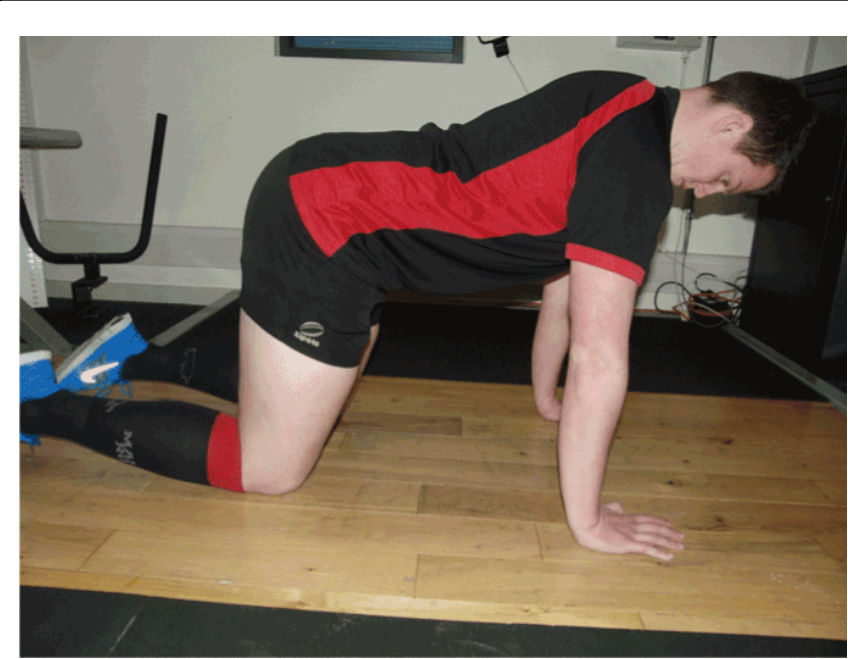

Figure 3: Four point kneeling assessment of proprioception starts

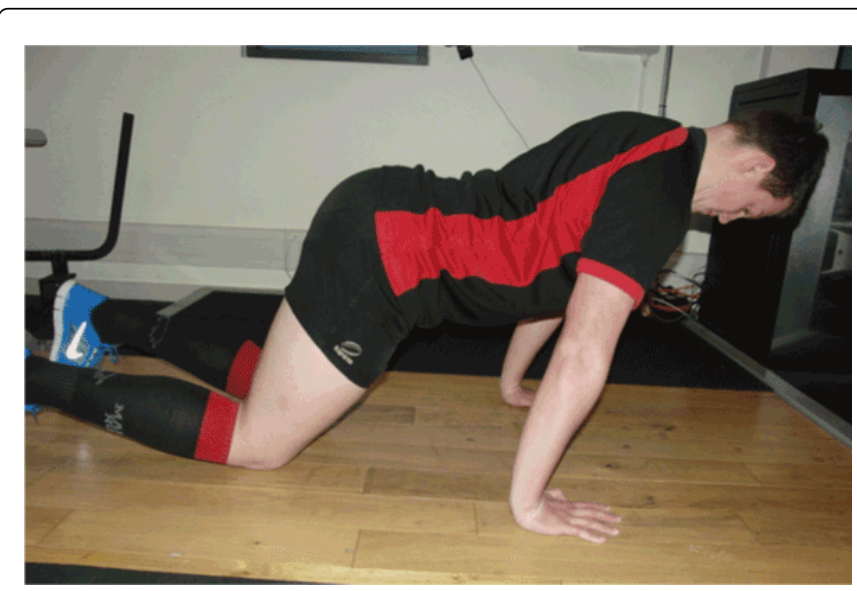

Figure 4: Four point kneeling assessment of proprioception ends

Although throwing is an open-chain movement, adaptations from closed chain exercises have been shown to impact positively on throwing velocity, and as effectively as open chain training in promoting maximal strength gains. Prokopy et al. [50] proposed that closed chain training for the shoulder conferred an advantage in proximal-distal force transduction via enhanced segmental stability or functional efficiency. Also, the unstable nature of the closed chain exercise using bodyweight suspension slings enables the closed chain group spent more time on the eccentric portion of a given exercise. It is possible that these additional eccentric stimuli play a role in throwing velocity improvements.

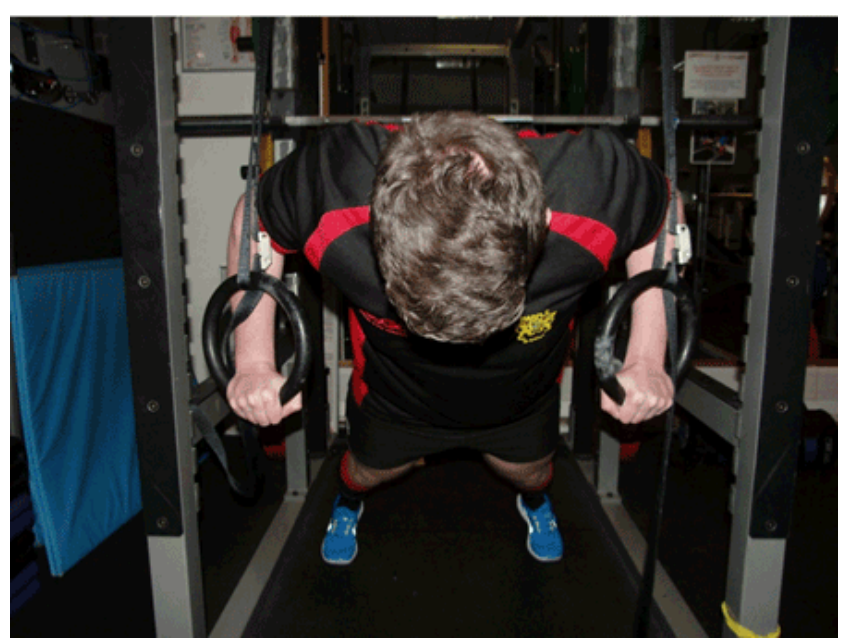

Figure 5: Closed chain rehabilitation to a less stable surface, suspension press up

Closed chain rehabilitation would then progress from a solid stable surface, to a less stable surface (e. g. wobble board, Swiss ball or sling suspension (Figures 5 and 6). The quality of the movement and exact local glenohumeral joint and scapula control needs to be monitored, as it is important to remember that arm movement, reflex stabilisation, postural control, and somato sensory perception are all components of an integrated action [51]. Once it is deemed appropriate, the exercises need to be carried out in more functional positions (rather than the early stage of lying positions), as body position has been shown to have a significant influence on an athlete's ability to replicate a target position and to be aware of upper limb movement [52]. The difficulty of the closed chain exercise can be progressed for end stage rehabilitation by incorporating reaction through unexpected perturbations, as in the mat based judo upper body walk drills seen above.

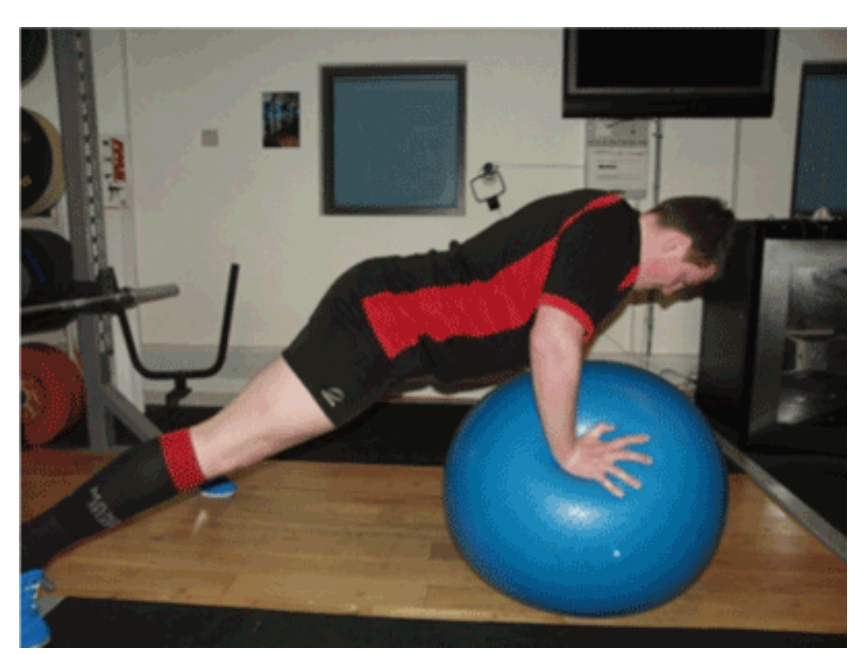

Figure 6: Closed chain rehabilitation to a less stable surface, Swiss ball press up 
Citation: Horsley I and Herrington L (2014) Optimal Management of Glenohumeral Joint Injuries in Athletes Playing Rugby. J Trauma Treat 3: 193. doi:10.4172/2167-1222.1000193

Page 5 of 8

The scapula acts as a link between the lower limb and trunk, the glenohumeral joint and upper limb, permitting effective transfer of forces and also acting to position the glenoid cavity to optimize lengthtension relationships around the glenohumeral joint. A stable scapula is thus vital for athletic shoulder function. Exercising in a scapula plane places the shoulder in a "safe zone" that minimizes glenohumeral shear, maximizes concavity/compression, and minimizes muscular activation.

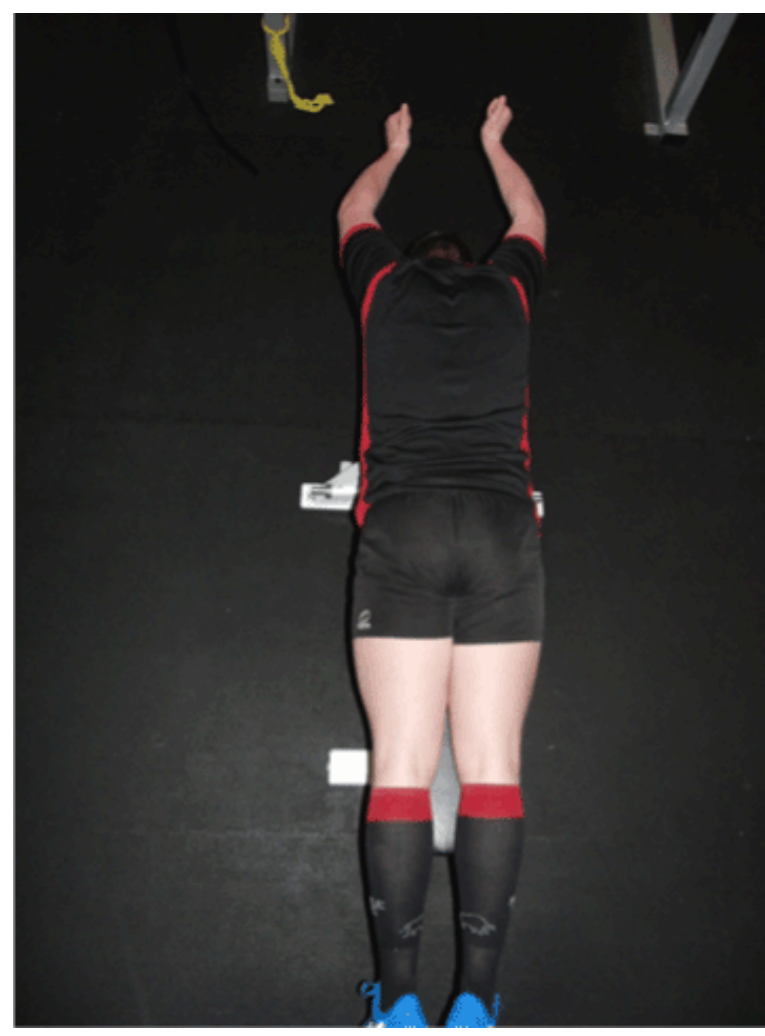

Figures 7: The use of scapula retraction exercise "I"

The work of the dynamic stabilizers is important due to the lack of adequate static stabilization from the bony anatomy. Abnormal scapula movement patterns are termed 'scapula dyskinesis' [53]. Improving posterior tilt, lateral rotation and upward rotation of the scapula is key to reducing shoulder pain and improving performance. The Scapula Assistance Test (SAT) and Scapula Retraction Test (SRT) can be used clinically to assess the athlete's potential responsiveness to exercise programs aimed at improving scapula stability [54]. Another important element to address is fatigue of the scapula stabilizers. Fatigue in the scapular retractors resulted in a reduction in shoulder rotation torque production in individuals with internal impingement [55]. Establishing a stable scapula platform is essential in minimizing stresses to the glenohumeral joint during overhead movements [56]. This enables the rotator cuff muscles to produce joint compression while minimizing translation of the humeral head [56]. Movement of the scapula and clavicle also influences the width of the sub acromial space. Scapular dyskinesis in pathologic populations often demonstrates decreased upward rotation, external rotation, and posterior tilt $[56,57]$. Oyama et al. [56] demonstrated that specific scapula retraction exercises effectively restored the normal scapular biomechanics, whilst activating the correct scapula stabilizing muscles.
The use of similar scapula retraction exercises, often named "I's, Y's, T's and W's" (Figures 7-10), are an important component of any shoulder rehabilitation or shoulder injury prevention programme.

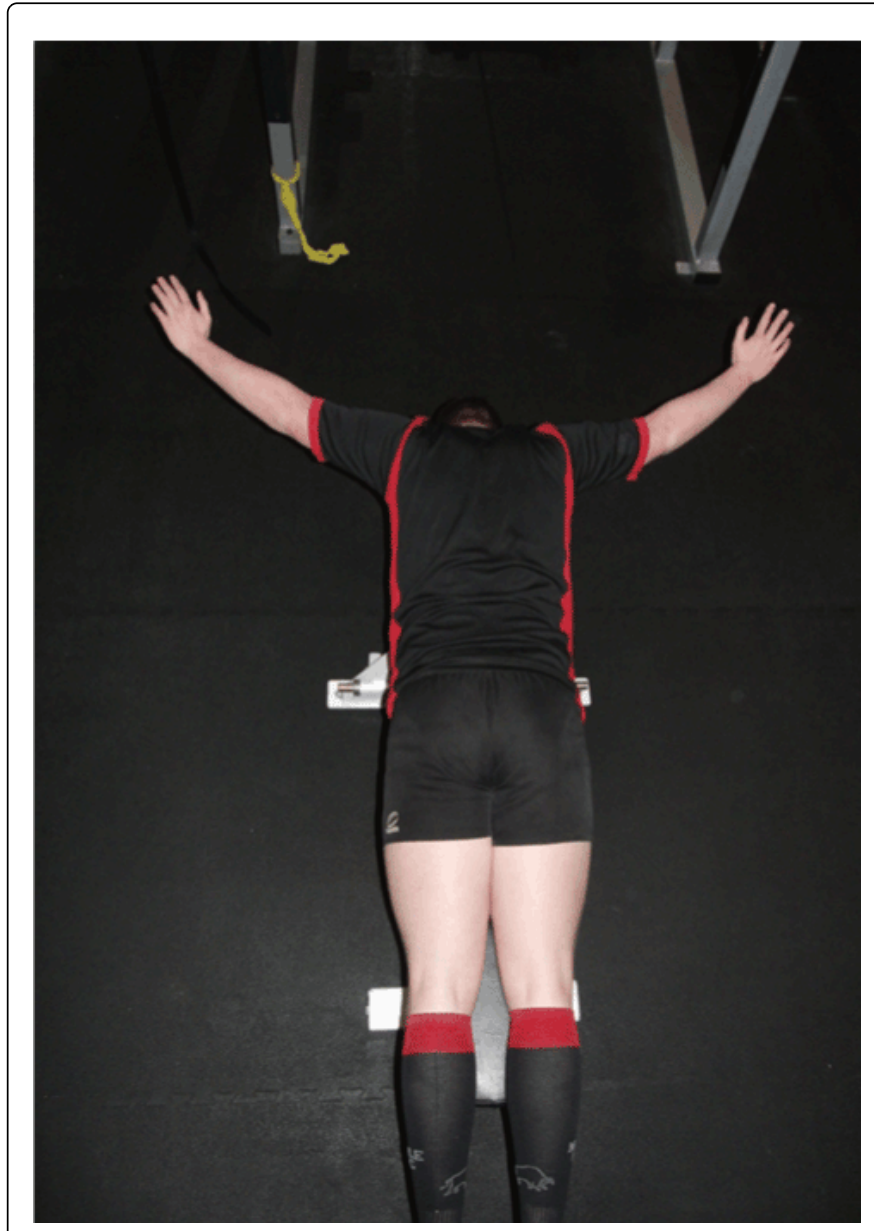

Figures 8: The use of scapula retraction exercise "Y"

\section{Plyometrics}

Once an athlete can tolerate the more controlled speeds used with most proprioceptive exercise, it is important that they are progressed to include plyometric exercises which attempt to match the speeds and functions required of the shoulder in their sport. Plyometric exercises involve an eccentric load or pre-stretch followed by a concentric contraction, which facilitates reflex joint stabilisation. These demands are seen in a number of overhead sporting tasks such as serving in tennis, and therefore need to be trained specifically. Stretch-shortening exercises use the elastic and reactive properties of a muscle to generate maximal force production [58] and these drills enhance the dynamic proprioception required in overhead sports. The hand to eye coordination required challenges the athlete in a way that seems to improve their performance with repeated and accurate practice of the skill. 
Citation: Horsley I and Herrington L (2014) Optimal Management of Glenohumeral Joint Injuries in Athletes Playing Rugby. J Trauma Treat 3: 193. doi:10.4172/2167-1222.1000193

Page 6 of 8

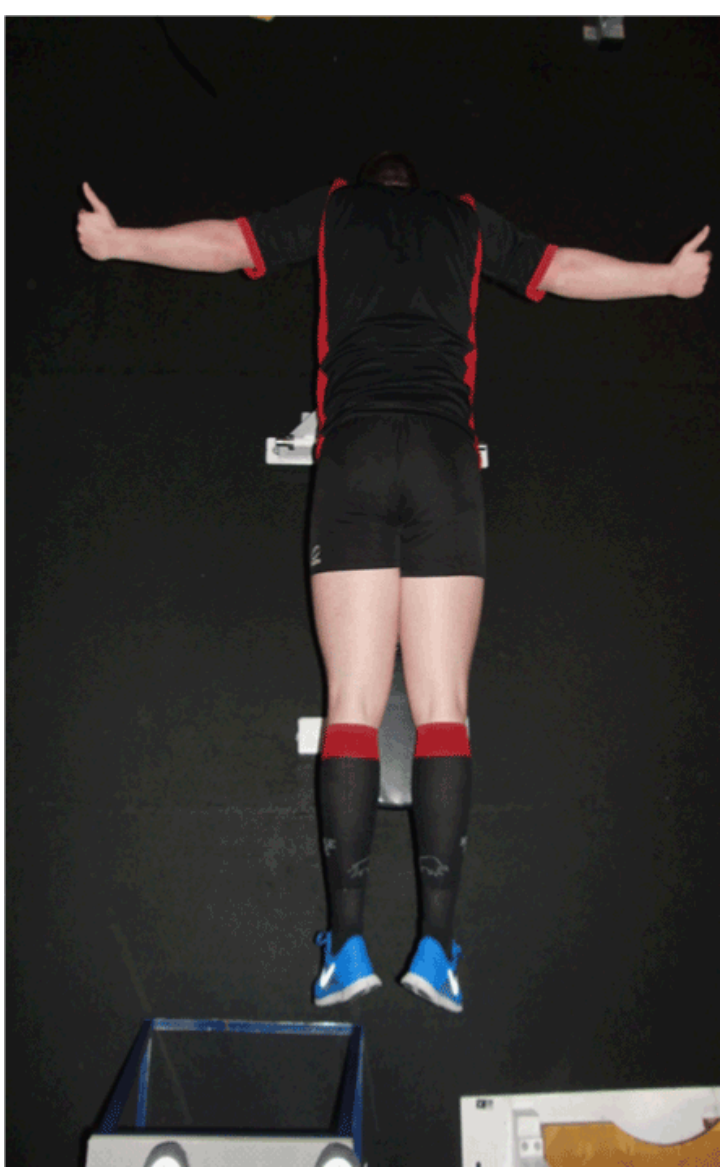

Figures 9: The use of scapula retraction exercise "T"

Common plyometric exercises include; throwing motions, trunk motions, resistive band exercises, ball/wall drills and plyometric pushups. Rotator cuff force couples appear to play a role in setting "stiffness" of joint prior to movement $[59,60]$. In order to retrain the reactive and protective capacity of the rotator cuff, plyometric exercises can begin with low level side lying external rotation (SLER) ball flips, which focus on early eccentric work for the infra-spinatus and posterior shoulder muscles (Figure 11). Posterior shoulder plyometrics can progress to the more challenging reverse catches, which address deceleration and control through greater range and at higher speeds, and also begin to incorporate more of the kinetic chain. Those athletes who are able to utilise their kinetic chain effectively, are able to offload the shoulder by dissipating forces elsewhere in the body. Delayed onset of Sub-scapularis during rapid shoulder external rotation has been demonstrated in pitchers with shoulder pain [60]. Low-level plyometric exercises can be used to facilitate feed forward protective activity of Sub-scapularis to produce joint stiffness in response to an external rotation perturbation in abduction, similar to an apprehension test position.

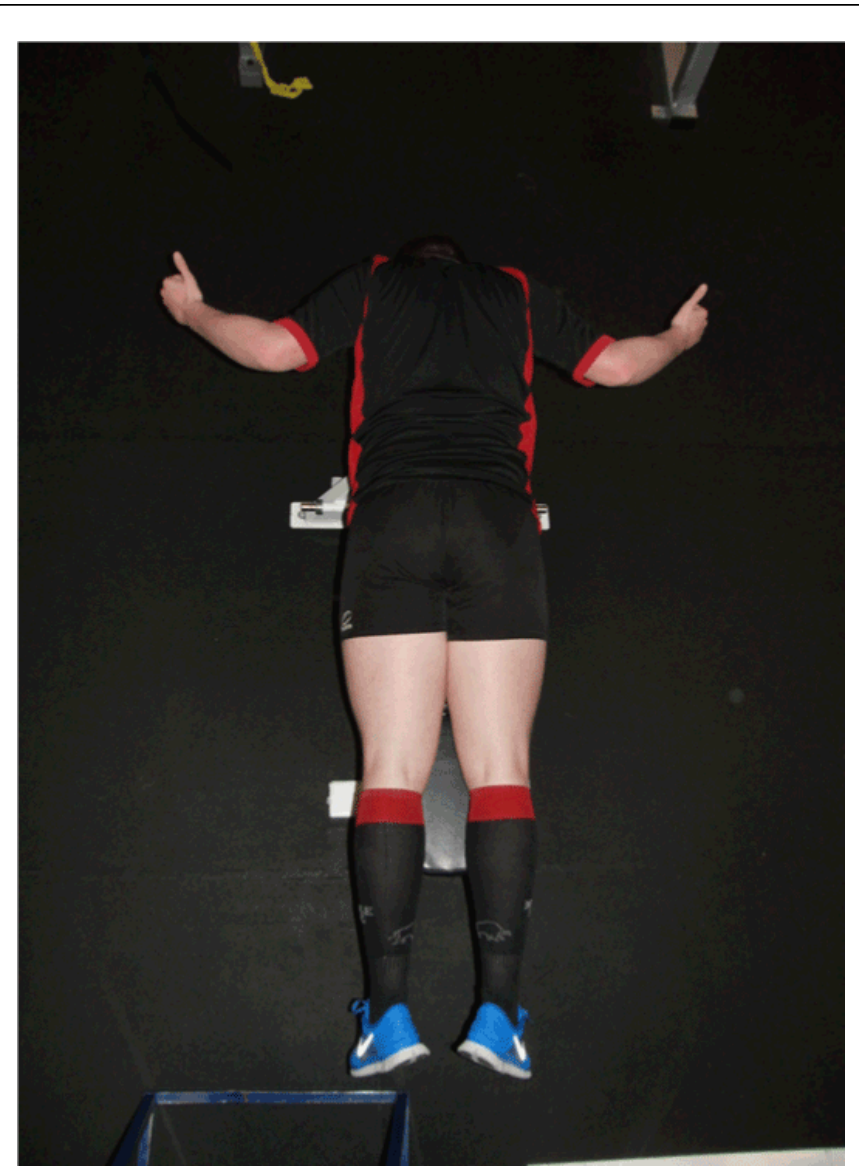

Figures 10: The use of scapula retraction exercise "W"

Progression to more demanding exercises in terms of speed and strength, is guided by the athlete's ability demonstrate excellent dynamic control around the shoulder, through full range, with good proprioceptive acuity. The foundation of good glenohumeral control is a well-sequenced connection from lower limb through the contact surface across the pelvis and trunk and into the scapula and requires efficient transfer of force through each link. Indeed, more than fifty percent of force generation in the throwing action comes from trunk and lower body [61]. Clearly, the shoulder starts at the feet! A lack of proximal activation can increase the distal loads for the same force or energy output, which, in turn, increases shearing forces on the inherently unstable shoulder. Rehabilitation exercises should therefore look to recreate and optimize efficient proximal segment activation in order to minimize the need for high force generation in the distal segments. 


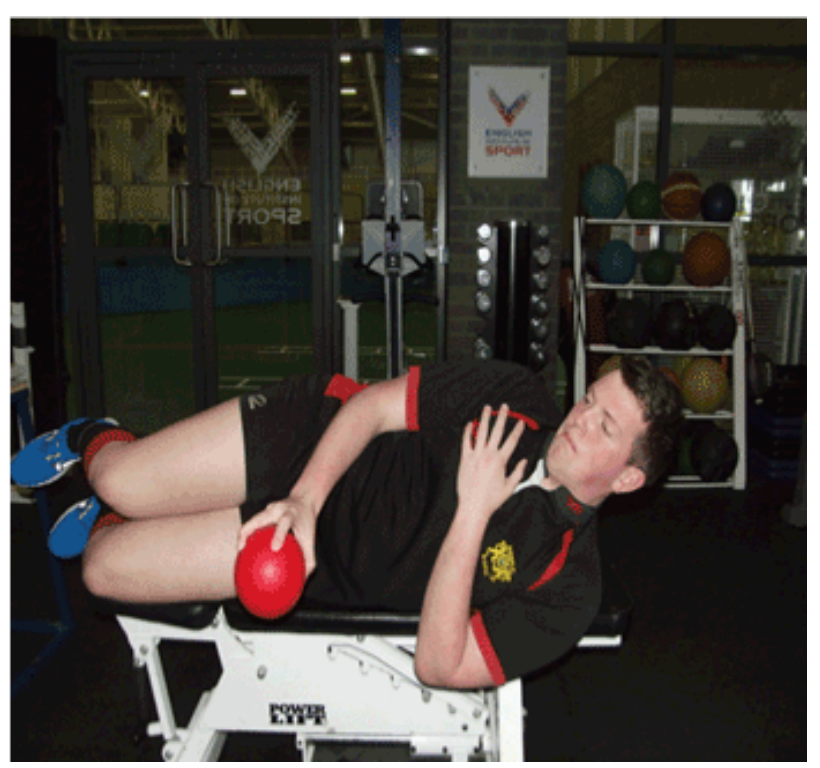

Figure 11: Ball flips, focusing on early eccentric work for the infraspinatus and posterior shoulder muscles

\section{Exercise Prescription}

In terms of exercise prescription, only the number of pain free repetitions that the patient can perform correctly with consistency should be carried out, rather that dictating a pre-determined number of repetitions and sets. Thus each exercise repetition goal is individualised for the specific demands of the shoulder of each patient to avoid fatigue-since motor control decreases rapidly with fatigue, which is accompanied by alterations in joint position awareness. Hence it is necessary to evaluate the quality of movement as the rehabilitation continuum progresses.

If the patient has a shoulder dysfunction which is associated with altered joint position sense, it is important to consider the exercises prescribed with respect of degree of challenge and the timing of their integration e. g. refrain from prescribing complex/challenging drills at end-range towards the end of a rehab session since they are likely to have decreased JPS and therefore be exposed to increased risk.

\section{Conclusion}

Functional stability of the athlete's shoulder is dependent on coactivation of the musculature as well as reactive neuromuscular characteristics. Injury to any of the soft tissue structures has been postulated as a cause of disruption of this neuromuscular mechanism. Treatment of such a dysfunction needs to consider proprioceptive training and rehabilitation, since the function of the shoulder joint is optimal when proprioception is normalized.

\section{References}

1. Bedford PJ, Macauley DC (1984) Attendances at a casualty department for sport related injuries. Br J Sports Med 18: 116-121.

2. van Mechelen W, Hlobil H, Kemper HC (1992) Incidence, severity, aetiology and prevention of sports injuries. A review of concepts. Sports Med 14: 82-99.
3. Watters DA, Brooks S, Elton RA, Little K (1984) Sports injuries in an accident and emergency department. Arch Emerg Med 1: 105-111.

4. Handcock P, Rehrer N, Beardmore A (2010) Return-to-play decision making in New Zealand "Super" Rugby. J Sci Med Sport 12: 88.

5. Junge A, Cheung K, Edwards T, Dvorak J (2004) Injuries in youth amateur soccer and rugby players--comparison of incidence and characteristics. Br J Sports Med 38: 168-172.

6. Takarada Y (2003) Evaluation of muscle damage after a rugby match with special reference to tackle plays. Br J Sports Med 37: 416-419.

7. Marshall SW, Waller AE, Dick RW, Pugh CB, Loomis DP, et al.. (2002) An ecologic study of protective equipment and injury in two contact sports. Int J Epidemiol 31: 587-592.

8. Mair SD, Zarzour RH, Speer KP (1998) Posterior labral injury in contact athletes. Am J Sports Med 26: 753-758.

9. Webb J, Bannister G (1992) Acromioclavicular disruption in first class rugby players. Br J Sports Med 26: 247-248.

10. Seward H, Orchard J, Hazard H, Collinson D (1993) Football injuries in Australia at the élite level. Med J Aust 159: 298-301.

11. Gerrard DF, Waller AE, Bird YN (1994) The New Zealand Rugby Injury and Performance Project: II. Previous injury experience of a rugbyplaying cohort. Br J Sports Med 28: 229-233.

12. Brooks JH, Fuller CW, Kemp SP, Reddin DB (2005) Epidemiology of injuries in English professional rugby union: part 1 match injuries. Br J Sports Med 39: 757-766.

13. http://www. medicalnewstoday. com/releases/248582. php

14. Usman J, McIntosh AS, Best JP (2011) The epidemiology of shoulder injuries in rugby union football. Br J Sports Med 45: 379.

15. Blanch P (2004) Conservative management of shoulder pain in swimming. Physical Therapy in Sport 3: 109-124.

16. Cholewinski JJ, Kusz DJ, Wojciechowski P, Cielinski LS, Zoladz MP (2008) Ultrasound measurement of rotator cuff thickness and acromiohumeral distance in the diagnosis of subacromial impingement syndrome of the shoulder. Knee Surg Sports TraumatolArthrosc 16: 408-414.

17. Borsa PA, Lephart SM, Kocker MS, Lephart SP (1994) functional assessment and rehabilitation of shoulder proprioception for glenohumeral instability. Journal of Sports Rehabilitation 3: 84-104.

18. Suprak DN, Osternig LR, van Donkelaar P, Karduna AR (2006) Shoulder joint position sense improves with elevation angle in a novel, unconstrained task. J Orthop Res 24: 559-568.

19. Janwantanakul P, Magarey ME, Jones MA, Dansie BR (2001) Variation in shoulder position sense at mid and extreme range of motion. Arch Phys Med Rehabil 82: 840-844.

20. Blasier RB, Carpenter JE, Huston LJ (1994) Shoulder proprioception. Effect of joint laxity, joint position, and direction of motion. Orthop Rev 23: 45-50.

21. Cain PR, Mutschler TA, Fu FH, Lee SK (1987) Anterior stability of the glenohumeral joint. A dynamic model. Am J Sports Med 15: 144-148.

22. Herrington L, Horsley I, Whitaker L, Rolf C (2008) Does a tackling task effect shoulder joint position sense in rugby players? Phys Ther Sport 9: 67-71.

23. Barden JM, Balyk R, Raso VJ, Moreau M, Bagnall K (2004) Dynamic upper limb proprioception in multidirectional shoulder instability. ClinOrthopRelat Res : 181-189.

24. Lephart SM, Henry TJ (1995) Functional rehabilitation for the upper and lower extremity. OrthopClin North Am 26: 579-592.

25. Myers JB, Lephart SM (2000) The role of the sensorimotor system in the athletic shoulder. J Athl Train 35: 351-363.

26. Herrington L, Horsley I, Rolf C (2010) Evaluation of shoulder joint position sense in both asymptomatic and rehabilitated professional rugby players and matched controls. Phys Ther Sport 11: 18-22.

27. Wilk KE, Arrigo C (1992) An integrated approach to upper extremity exercises. OrthopPhysTherClin N Am 1: 337-360. 
Citation: Horsley I and Herrington L (2014) Optimal Management of Glenohumeral Joint Injuries in Athletes Playing Rugby. J Trauma Treat 3: 193. doi:10.4172/2167-1222.1000193

Page 8 of 8

28. Scher S, Anderson K, Weber N, Bajorek J, Rand K, et al.. (2010) Associations among hip and shoulder range of motion and shoulder injury in professional baseball players. J Athl Train 45: 191-197.

29. Scolaro JA, Kelly JD (2010) The thrower's shoulder. University of Pennsylvania Orthopaedic Journal 20: 53-57.

30. Clabbers KM, Kelly JD, Bader D, Eager M, Imhauser C, et al.. (2007) Effect of posterior capsule tightness on glenohumeral translation in the late-cocking phase of pitching. J Sport Rehabil 16: 41-49.

31. Burkhart S, Morgan C, Kibler WB (2003) The disabled throwing shoulder:Spectrum of pathology Part II: Evaluation and treatment of SLAP lesions in throwers. Arthroscopy, 19: 531-539.

32. Myers JB, Laudner KG, Pasquale MR, Bradley JP, Lephart SM (2006) Glenohumeral range of motion deficits and posterior shoulder tightness in throwers with pathologic internal impingement. Am J Sports Med 34: 385-391.

33. Sauers E, August A, Snyder A (2007) Fauls stretching routine produces acute gains in throwing shoulder mobility in collegiate baseball players. J Sport Rehabil 16: 28-40.

34. Thomas S, Swanik C, Swanik K, Nazarian L, Bartolozzi A, et al.. (2009) A bi-lateral posterior capsule thickness and its correlation with glenohumeral internal rotation in collegiate baseball players. Journal of Athletic Training 44: S-42.

35. Voight ML, Hardin JA, Blackburn TA, Tippett S, Canner GC (1996) The effects of muscle fatigue on and the relationship of arm dominance to shoulder proprioception. J Orthop Sports PhysTher 23: 348-352.

36. Myers JB, Guskiewicz KM, Schneider RA, Prentice WE (1999) Proprioception and neuromuscular control of the shoulder after muscle fatigue. J Athl Train 34: 362-367.

37. Tsai NT, McClure PW, Karduna AR (2003) Effects of muscle fatigue on 3-dimensional scapular kinematics. Arch Phys Med Rehabil 84: 1000-1005.

38. Ebaugh DD, McClure PW, Karduna AR (2006) Scapulothoracic and glenohumeral kinematics following an external rotation fatigue protocol. J Orthop Sports PhysTher 36: 557-571.

39. Ellenbecker TS, Cools A (2010) Rehabilitation of shoulder impingement syndrome and rotator cuff injuries: an evidence-based review. Br J Sports Med 44: 319-327.

40. Lintner D, Mayol M, Uzodinma O, Jones R, Labossiere D (2007) Glenohumeral internal rotation deficits in professional pitchers enrolled in an internal rotation stretching program. Am J Sports Med 35: 617-621.

41. Laudner KG1, Sipes RC, Wilson JT (2008) The acute effects of sleeper stretches on shoulder range of motion. J Athl Train 43: 359-363.

42. McClure P1, Balaicuis J, Heiland D, Broersma ME, Thorndike CK, et al. (2007) A randomized controlled comparison of stretching procedures for posterior shoulder tightness. J Orthop Sports PhysTher 37: 108-114.

43. Ellenbecker TS (2004) In Clinical Examination of the Shoulder - Elsevier Saunders, St Louis, Missouri, USA.

44. Wilk KE, Obma P, Simpson CD, Cain EL, Dugas JR, et al.. (2009) Shoulder injuries in the overhead athlete. J Orthop Sports PhysTher 39: 38-54.
45. Horsley IG, Herrington LC, Rolf C (2010) Does a SLAP lesion affect shoulder muscle recruitment as measured by EMG activity during a rugby tackle? J OrthopSurg Res 5: 12.

46. Herrington L, Horsley IG (2013) Effects of latissimusdorsi length on shoulder flexion in canoeists, swimmers, rugby players, and controls. Journal of Sport and Health Science 3: 60-63.

47. Magarey ME, Jones MA (2003) Dynamic evaluation and early management of altered motor control around the shoulder complex. Man Ther 8: 195-206.

48. Magarey ME, Jones MA (2003) Specific evaluation of the function of force couples relevant for stabilization of the glenohumeral joint. Man Ther 8: 247-253.

49. Laudner KG, Meister K, Kajiyama S, Noel B (2012) The relationship between anterior glenohumeral laxity and proprioception in collegiate baseball players. Clin J Sport Med 22: 478-482.

50. Prokopy MP, Ingersoll CD, Nordenschild E, Katch FI, Gaesser GA, et al. (2008) Closed-kinetic chain upper-body training improves throwing performance of NCAA Division I Softball players. J Strength Cond Res 22: $1790-1798$

51. Guido JA Jr, Stemm J (2007) Reactive Neuromuscular Training: A Multilevel Approach to Rehabilitation of the Unstable Shoulder. N Am J Sports Phys Ther 2: 97-103.

52. Janwantanakul P (2003) The effect of body orientation on shoulder proprioception. Phys Ther Sport 4: 67-73.

53. Kibler WB, Sciascia A (2010) Current concepts: scapular dyskinesis. Br J Sports Med 44: 300-305.

54. Kibler B (2003) Management of the scapula in glenohumeral instability. Techniques in Shoulder \& Elbow Surgery 4: 89-98.

55. Tyler TF, Cuoco A, Schachter AK, Thomas GC, McHugh MP (2009) The effect of scapular-retractor fatigue on external and internal rotation in patients with internal impingement. J Sport Rehabil 18: 229-239.

56. Oyama S, Myers JB, Wassinger CA, Lephart SM (2010) Threedimensional scapular and clavicular kinematics and scapular muscle activity during retraction exercises. J Orthop Sports PhysTher 40: 169-179.

57. Ludewig PM, Phadke V, Braman JP, Hassett DR, Cieminski CJ, et al. (2009) Motion of the shoulder complex during multiplanar humeral elevation. J Bone Joint Surg Am 91: 378-389.

58. Davies GJ, Matheson JW (2001) Shoulder Plyometrics Sports Medicine and Arthroscopy Review. 9: 1-18.

59. David G, Magarey ME, Jones MA, Dvir Z, Turker KS, et al.. (2000) EMG and strength correlates of selected shoulder muscles during rotations of the glenohumeral joint. Clinical Biomechanics 15: 95-102.

60. Hess SA, Richardson C, Darnell R, Friis P, Lisle D, et al.. (2005) Timing of rotator cuff activation during shoulder external rotation in throwers with and without symptoms of pain. J Orthop Sports PhysTher 35: 812-820.

61. Fleisig GS, Andrews JR, Dillman CJ, Escamilla RF (1995) Kinetics of baseball pitching with implications about injury mechanisms. Am J Sports Med 23: 233-239. 